\title{
TECNOLOGIAS DIGITAIS DE INFORMAÇÃO E COMUNICAÇÃO NA EDUCAÇÃO EM SAÚdE NA ESCOLA: ANÁLISE DO USO DE UM JOGO VOLTADO PARA ADOLESCENTES
}

\author{
Claudilene Moura Perim ${ }^{1}$, Miriam Struchiner ${ }^{2}$, Tais Rabetti Giannella ${ }^{3}$ \\ 1,2,3 Laboratório de Tecnologias Cognitivas - Núcleo de Tecnologia Educacional para a \\ Saúde - Universidade Federal do Rio de Janeiro (UFRJ) \\ lena.perim@uol.com.br, miriamstru@gmail.com, taisrg@yahoo.com.br
}

\begin{abstract}
This study aimed to analyze the perception of a group of students and teachers at a public school in Rio de Janeiro on the use of a game for teenagers mediated Digital Technologies of Information and Communication (TDIC) as a pedagogical strategy for mobilizing content health. Participated in this study> two teachers (Science and Mathematics), the Pedagogical Coordinator and 37 students in a class in 9th grade. The results indicated a positive evaluation, but with some technical challenges related to the use of TDIC. The playful nature of the activity provided a favorable environment for discussion of complex issues to the public. Furthermore, the use of TDIC enhanced the dynamics of the game, favoring research and critical analysis of information and collaboration among students.
\end{abstract}

Resumo. O objetivo deste estudo foi analisar a percepção de um grupo de alunos e professores de uma escola municipal do Rio de Janeiro sobre o uso de um jogo para adolescentes mediado por Tecnologias Digitais de Informação e Comunicação (TDIC) como estratégia pedagógica para mobilizar os conteúdos de saúde. Participaram dessa pesquisa dois professores (Ciências e Matemática), a Coordenadora Pedagógica e 37 alunos de uma turma do $9^{\circ}$ ano. Os resultados indicaram uma avaliação positiva, porém com alguns desafios técnicos relacionados ao uso da TDIC. O caráter lúdico da atividade proporcionou um ambiente favorável para discussão de temáticas complexas para esse público. Além disso, o uso de TDIC potencializou a dinâmica do jogo, favorecendo a pesquisa e análise crítica de informações e a colaboração entre os alunos.

\section{Introdução}

Proporcionar condições aos adolescentes para apropriação crítica de conhecimentos sobre saúde, cujas reflexões e discussões repercutam em suas vidas em sociedade, desafia a escola a introduzir estratégias pedagógicas que incorporem linguagens e práticas relacionadas ao cotidiano dessa população, de modo a tornar este processo participativo e prazeroso (IERVOLINO, 2000).

$\mathrm{Na}$ abordagem de temas relacionados à saúde, a escola enfrenta diversos desafios, tais como a escassez de conteúdos e materiais de apoio e a formação inadequada de professores (Monteiro, 2012). Estes fatores, associados ao hiato existente entre os conteúdos abordados e a realidade social dos adolescentes, refletem na falta de 
interesse por parte destes jovens na participação nas atividades educativas propostas pelos professores. Portanto, torna-se necessário buscar novas práticas pedagógicas que aproximem a escola do cotidiano dos alunos, favorecendo a construção de um conceito ampliado de saúde e motivando sua participação ativa no processo de construção desse conhecimento.

Neste sentido, Yonekura \& Soares (2010) apontam o jogo educativo como uma alternativa viável para facilitar a discussão de temas relevantes sobre saúde, como diabetes, infecções respiratórias infantis, cuidados no puerpério, e até mesmo temas mais sensíveis como drogas e AIDS, podendo ser utilizados em diversas situações, envolvendo crianças, adolescentes e adultos.

Para Mattar (2010), na discussão sobre a necessária de transformação das práticas pedagógicas, as Tecnologias Digitais de Informação e Comunicação (TDIC) têm sido situadas como importantes ferramentas de inovação. Segundo o autor, estas estão cada vez mais presentes no cotidiano da nossa sociedade, sendo parte integrante da vida de vários jovens. Assim, torna-se necessário refletir sobre a sua utilização no ambiente educacional e como o aluno se apropria desta tecnologia no seu processo de aprendizagem.

\section{Objetivo:}

Analisar a perspectiva de alunos e professores sobre a utilização de um jogo mediado pelas Tecnologias Digitais de Informação e Comunicação como estratégia para abordar temas relacionados à saúde do adolescente no contexto de práticas educativas em uma escola municipal do Rio de Janeiro.

\section{Metodologia}

\section{Contexto e Sujeitos do Estudo}

A definição do campo de estudo teve como base o projeto "Com-viver, Com-Ciência e Cidadania”, que consistiu na realização de atividades, relacionadas à temática da saúde, integradas aos conteúdos de todas as disciplinas, ao longo de uma semana em uma turma do $9^{\circ}$ ano de uma escola municipal do Rio de Janeiro. O objetivo do projeto foi construir, com professores e alunos, a compreensão de que ter uma vida saudável é mais do que ter um corpo saudável e que, portanto, saúde é um tema amplo, complexo e interdisciplinar. Participaram da aplicação do jogo em sala de aula e do estudo, as professoras de Ciências e Matemática, a Coordenadora pedagógica e os 37 alunos do $9^{\circ}$ da turma 1901.

\section{Materiais}

A primeira versão do "Jogo Saúde do Adolescente" foi desenvolvida no âmbito do Programa Saúde na Escola (Secretaria Municipal de Saúde) e aplicada em uma escola do Rio de Janeiro. Na presente pesquisa, alguns recursos foram adaptados para integrar o uso do computador e estimular os alunos a pesquisarem durante o jogo. O jogo Saúde do Adolescente é composto por: (1) Um tabuleiro em forma de trilha 1,50 x 1,50; (2) Cinco cones coloridos; (3) Um dado; (4) 50 fichas com perguntas e repostas digitalizadas de diversos temas relacionados à saúde do adolescente; (5) Computador com acesso à Internet; e (6) Materiais e links para pesquisar as respostas. 


\section{Coleta e Tratamento dos dados}

As informações foram coletadas por meio de observação participante, de entrevistas (gravadas) com professores e de uma sessão de discussão com alunos ocorrida no último dia das práticas educativas desenvolvidas ao longo da semana. Elaborou-se um roteiro orientador para auxiliar a coleta, o registro e a análise de dados. Para avaliar a opinião dos alunos sobre a atividade, foi elaborado um questionário, respondido ao final da atividade. As sínteses das percepções de professores e alunos, objeto do presente estudo, são apresentadas nos quadros um e dois.

A análise dos dados buscou identificar a percepção dos sujeitos quanto à utilização do jogo com temas relacionados à saúde de adolescentes, às mudanças no conhecimento sobre saúde por parte dos adolescentes, ao uso de TDICs permeando as atividades do jogo, além de aspectos relacionados à motivação e ao engajamento dos participantes nas atividades propostas.

\section{Resultados e Discussão:}

As análises dos dados e da observação apontaram, em geral, para uma avaliação positiva dos participantes em relação ao uso do jogo para a construção de conhecimentos em Saúde pelos adolescentes. O rompimento da rotina da escola e o uso do computador durante as atividades marcaram as falas de educadores e alunos. $\mathrm{Na}$ pesquisa de opinião dos alunos sobre o jogo, a atividade foi classificada como "boa" ou "ótima" por $95 \%$ dos alunos e o mesmo percentual considerou que o jogo despertou o interesse para assuntos relacionados com Saúde.

Os aspectos marcantes da experiência encontram-se na síntese das observações dos pesquisadores sobre a dinâmica da atividade com o jogo em sala de aula, a seguir: (1) inicialmente, as regras não estavam bem entendidas pelos alunos, demandando mais tempo para organizar a turma e iniciar a atividade; (2) o ritmo do jogo precisou ser dosado para permitir o aprofundamento na discussão das dúvidas e temas das perguntas; (3) não houve interferência na formação dos grupos de alunos para o jogo; os alunos se agruparam de acordo com suas afinidades; (4) não foi observado nenhum tipo de segregação entre meninos e meninas: a maioria se organizou em grupos mistos; (5) a maioria dos alunos participou ativamente das atividades, mas houve alguns que dispersaram quando não era sua vez de jogar; (6) em geral, o clima de competição funcionou como fator de motivação, mas para alguns alunos a competição era o foco da atividade; (7) houve bastante interação e participação por parte dos alunos; (8) muitos alunos utilizaram o jogo para tirar dúvidas sobre os temas abordados pelo jogo (sexualidade, gravidez na adolescência, bullying); (9) clima muito positivo durante a atividade; ao final, os alunos pediram para repetir a atividade.

Falas sobre o uso do computador e da Internet durante as atividades foram recorrentes nos dados coletados. Os professores entrevistados reconheceram que foram estimulados a desenvolver suas habilidades e familiaridade com a tecnologia e com os conteúdos por ela disponibilizados. Já os alunos, disseram sentirem-se motivados a usar seus computadores na busca objetiva de informações e respostas aos desafios que lhes foram colocados.

Os educadores entrevistados enfatizaram o caráter motivador e mobilizador do jogo na turma e reconheceram que o ambiente de competição com descontração estimulou tanto o espírito de equipe como a participação individual na atividade. A 
temática saúde de adolescentes despertou grande interesse dos alunos que se sentiram à vontade para esclarecer suas dúvidas e expor abertamente seus pontos de vista.

\section{Quadro 1: Síntese dos resultados obtidos a partir da sessão de discussão com alunos}

\begin{tabular}{|c|c|}
\hline Referências ao jogo & $\begin{array}{l}\text { "Jogo foi ótimo" } \\
\text { "Jogo foi bem organizado" } \\
\text { "Possibilita trabalhar outros conteúdos além da Saúde" } \\
\text { "Quebrou a rotina" } \\
\text { "Tive que me familiarizar mais com as ferramentas disponibilizadas pelo computador" }\end{array}$ \\
\hline O que funcionou? & $\begin{array}{l}\text { Feedback positivo dado pelos alunos } \\
\text { Serviu para a mobilização de alunos } \\
\text { Quebra da rotina da escola } \\
\text { Tempo adequado para as atividades } \\
\text { Trabalho em grupo } \\
\text { Uso do computador durante as atividades } \\
\text { Competição como fator de motivação para os alunos } \\
\text { Interação entre alunos } \\
\text { Oportunidade para os alunos lidarem lidar com diversidade de opiniões } \\
\text { Exposição do professor a novas ferramentas pedagógicas }\end{array}$ \\
\hline $\begin{array}{l}\text { O que não } \\
\text { funcionou? }\end{array}$ & $\begin{array}{l}\text { Tempo insuficiente para as atividades } \\
\text { Participação limitada dos professores no planejamento } \\
\text { Indisponibilidades frequentes de acesso à internet } \\
\text { Necessidade de planejamento prévio para a inclusão deste tipo de atividade no currículo do professor }\end{array}$ \\
\hline $\begin{array}{l}\text { Comentários sobre a } \\
\text { abordagem do tema } \\
\text { saúde }\end{array}$ & $\begin{array}{l}\text { Professor participar no planejamento } \\
\text { Falta de integração entre os professores das diversas matérias } \\
\text { Trabalhar outros temas (integração racial, questões sociais) } \\
\text { Este tipo de atividade deve ser incluída o planejamento anual da escola }\end{array}$ \\
\hline Sugestões & $\begin{array}{l}\text { Incluir a saúde como eixo para abordar outros temas dentro de cada disciplina (fatores sociais e } \\
\text { ambientais) } \\
\text { Ampliar o entendimento de saúde abordando o tema através de várias disciplinas (matemática, } \\
\text { educação física, geografia) } \\
\text { Ter um produto tangível ao final da atividade }\end{array}$ \\
\hline
\end{tabular}

Quadro 2: Síntese dos resultados obtidos a partir da sessão de discussão com alunos

\begin{tabular}{|l|l|}
\hline Referências ao jogo & $\begin{array}{l}\text { "O jogo quebrou a rotina. Não foi uma aula chata” } \\
\text { "Aprender se divertindo” } \\
\text { "Aprendemos coisas que achávamos que já sabíamos” }\end{array}$ \\
\hline O que funcionou? & $\begin{array}{l}\text { Uso do computador para pesquisar as respostas } \\
\text { Um assunto (bullying) puxando discussões sobre vários assuntos (transversalidade) } \\
\text { Estimulou o trabalho em grupo }\end{array}$ \\
\hline $\begin{array}{l}\text { O que não } \\
\text { funcionou? }\end{array}$ & $\begin{array}{l}\text { Enquanto um grupo jogava, outros não prestavam atenção (dispersão de alguns alunos } \\
\text { durante a atividade). }\end{array}$ \\
\hline $\begin{array}{l}\text { Comentários sobre a a } \\
\text { abordagem do tema } \\
\text { saúde }\end{array}$ & Discussão de temas difíceis de conversar e que não se conhece bem \\
\hline Sugestões & Repetir este tipo de atividade \\
\hline
\end{tabular}


Os pesquisadores observaram a importância de comunicar os objetivos e as regras do jogo claramente e anteriormente ao seu início, de modo a evitar que o foco por parte dos alunos fique no jogo em si ao invés de na aprendizagem. Outro aspecto observado está relacionado ao ritmo com que é conduzido o jogo, que deve ser dosado de modo a permitir o aprofundamento nas discussões dos temas levantados pelas perguntas.

\section{Considerações Finais:}

No ambiente escolar, o planejamento tem papel fundamental para que o jogo alcance resultados efetivos de construção de conhecimento por parte dos alunos. O jogo deve ser parte do planejamento pedagógico do professor e da instituição e sua utilização deve ser precedida de uma criteriosa preparação. Além disto, analisar e entender o contexto social em que a escola e seus alunos estão inseridos, levando seus conflitos e limitações para a dinâmica do jogo, é fundamental para que este atinja seus objetivos e torne-se uma ferramenta de transformação

A inclusão das TICs aportou motivação adicional a professores e alunos, mas também alguns desafios, pois se tratando da prática pedagógica, percebe-se necessidade de melhorar o processo educacional de modo a compreender a relevância de uma alfabetização científico-tecnológica reflexiva Sem o pleno domínio das ferramentas disponibilizadas pela tecnologia por parte dos professores, coloca-se em risco sua efetividade. A combinação entre jogo físico e internet trouxe dinâmica, diversidade e movimentação na atividade.

\section{Referências}

IERVOLINO, Solange Abrocesi. Escola promotora da saúde: um projeto de qualidade de vida. 2000. Dissertação (Mestrado em Serviços de Saúde Pública) - Faculdade de Saúde Pública, Universidade de São Paulo, São Paulo, 2000. Disponível em: $<$ http://www.teses.usp.br/teses/disponiveis/6/6135/tde-01072006-211720/>. Acesso em: 2013-08-10.

MATTAR, João. Games em Educação. Como os nativos digitais aprendem. Pearson Prentice Hall: São Paulo, 2010.

MONTEIRO, P. A saúde nos livros didáticos no Brasil: concepções e tendências nos anos iniciais do ensino fundamental. 2012. Tese (Doutorado em Educação) Faculdade de Educação, Universidade de São Paulo, São Paulo, 2012. Disponível em: $\quad<$ http://www.teses.usp.br/teses/disponiveis/48/48134/tde-04072012-131023/>. Acesso em: 2012-11-20.

YONEKURA, Tatiana; SOARES, Cássia Baldini. O jogo educativo como estratégia de sensibilização para coleta de dados com adolescentes. Rev. Latino-Am. Enfermagem, Ribeirão Preto, v. 18, n. 5, Out. 2010. Disponível em <http://www .scielo.br/scielo.php?script $=$ sci_arttext\&pid=S0104-11692010000500018\&lng= en\&nrm=iso> . Acesso em 9 de Março de 2013. 